\title{
Rapid Virologic Response
}

National Cancer Institute

\section{Source}

National Cancer Institute. Rapid Virologic Response. NCI Thesaurus. Code C120597.

A finding of aviremia at a specified timepoint, early during the treatment period. 